\title{
TEAMWORK SKILLS IN THE CHEMISTRY AND BIOTECHNOLOGY LABORATORIES
}

\author{
C.A. Santos, A.G. Gomes \\ Escola Superior de Tecnologia do Barreiro do Instituto Politécnico de Setúbal (PORTUGAL)
}

\begin{abstract}
Nowadays, it is increasingly necessary not only to develop good technical skills, but also communication and team work skills, which are not formally taught in engineering courses. Among these, the authors focused on the ability to work as a team, in laboratorial classes of a Bachelor course in biotechnology, and to know how to relate to others and work collaboratively, which are competences that have been increasingly appreciated by employers. Therefore, in the present paper the authors intend to make an analysis of the self and peer-assessment of students, as members of a given group and to demonstrate some aspects of group dynamics in the chemical and biological area, to identify dysfunctional groups, and to establish the conditions to reduce them, and, lastly, to develop the critical thinking and working constructively in a team.
\end{abstract}

The approach adopted employed the online tool SparkPlus, which presents a survey regarding teamworking skills to be answered by all team members. The data was obtained from laboratory group teams of students from the second year of Biotechnology Bachelor at polytechnic institute of Setúbal in Portugal for three academic years.

Results identified students' larger difficulties: as writing the lab report; secondly the leadership problems, and thirdly the number crunching. These skills need to be developed in future work during the course. On the other hand, students registered less difficulties in efficient functioning of a group.

Also, results from group dynamics, have identified over-rating and under-rating students in the assessment. These findings will allow actions to be taken in order to balance a given team, namely in terms of identification of the role of each member for a given task.

Keywords: Sparkplus, teamwork, skills, self and peer assessment.

\section{INTRODUCTION}

The self and peer assessment of students during classes has been used for three decades now, and it is applied with the main purpose to improve learning outcomes and to understand the notion of the student's effort and point of view in the team's work. This kind of procedure aims to give students an opportunity to practice, assess and provide feedback on their own and peers performance during the learning process they are going through. Moreover, it can be used to develop critical thinking and judgement skills that are mandatory professional skills and are not usually formally practiced in science/engineer courses. When applying this method, teachers aim to look for a way to fairly evaluate the work produced by a team of students considering also their individual contribution [1].

Several studies have referred to the importance of teamwork as a component of engineering practice, and for that reason courses often include ways to develop this skill [2]. Previous work has shown how self and peer assessment activities applied to civil engineering students contributed to encouraging student engagement, using the online software SparkPlus [2, 3].

SparkPlus [4] is a self- and peer-assessment system developed at the University of Technology, Sydney. It is a rating-based system, where students fill out an online quiz assessing their and their teammates' contributions. The pedagogical tool SparkPlus was designed to facilitate the use of self and peer assessment of all participants in a given project, and students rate their own and their peer's performance in the team work according to a four-category system: (1) Efficient functioning of a group, (2) Leadership, (3) Number crunching, and (4) Writing report. Each category is further divided in several criteria that helps the student to answer easily to the quiz.

As for Efficient functioning of group (1), the criteria were: (1.a) helping the group to function well as a team; (1.b) level of enthusiasm and participation; (1.c) organising the team and ensuring that the work was accomplished in a given period; (1.d) performing tasks efficiently and suggesting ideas; (1.e) understanding what is required for a given task. In category (2), leadership- the criteria were: (2.a) 
chasing and coordinating, (2.b) assignment of tasks to each member and decide deadline dates to gather information, (2.c) integrating the developed work to answer a given problem or to write a report. In category (3)-Number crunching the criteria were: (3.a) analysis and cross checking, (3.b) data and formula entry, and formatting; (3.c) finding out how to solve a given problem, (3.d) getting new data. And finally, the category (4), writing the report the following criteria were: (4.a) editing format, style, grammar, spelling; (4.b) getting extra references and appraising their usefulness;(4.c) producing diagrams, figures, tables; (4.d) typing.

Also, to make the tool more friendly to use, students had to rate all these criteria in a slider scale from Well Below Average (WB) to Well Above Average (WA). Based on the ratings of each group member against each criterion, SparkPlus tool [4] automatically calculates two weighting factors, corresponding to each group members' contribution in a team project. The Relative Performance Factor (RPF) is a weighting factor that correlates both the self and peer rating of a student's contribution. It is typically used to change a team assessment mark to an individual mark by multiplying the team's assessment value by the individual's RPF:

Individual assessment mark= team assessment mark * Individual's RPF

The Self-Assessment to Peer Assessment (SA/PA) factor is the ratio of a student rating himself or herself compared to the average rating of his or her contribution by their peers. The SA/PA factor has a strong feedback value and so it develops the critical reflection and evaluation skills. Moreover, a SA/PA greater than one means that a student has rated his or her own performance higher than the average rating he or she received from their peers. The opposite case is also true, i.e., for a SA/PA lower than one, means that a student has rated his or her own performance lower than the average rating he or she received from their peers. Typically, SA/PA factors between 0.95 and 1.05 (student's assessment is within approximately $10 \%$ of his or her peers) reflect that the assessment of selfcontribution is roughly in agreement with the average assessment of peer contribution by the rest of the team [5].

It has been found a correlation between the self-evaluation and performance of students, that states high-performing students tend to underrate themselves, and low-performers students overrate themselves, although some authors prefer to say that high performers were more accurate ratters [6].

It was also found in a case study that more males tend to overrate and underrate themselves than females, when considering over-rating is defined as a SA/PA score of $\geq 1.20$ and under-rating is defined as a SA/PA score of $\leq 0.80$. In the presence of such values, these students have been advised and encouraged to become more accurate about their efforts in group work [7]. In the case of over-rating, often these are students who are attempting to gain an unfair advantage by inflating their ratings of themselves compared to the ratings of their peers [7].

Both SA/PA and RPF factors can be calculated as overall factors and as partial factors for each criteria category for each team member, providing additional information about the student's skills.

In this study, the SparkPlus tool was applied to a hands-on curriculum unit of Laboratory, which comprises several laboratory procedures to demonstrate some of the concepts lectured in the curriculum units that take place in the same semester, of the second year of the undergraduate course of Biotechnology (laboratory IIIB in the first semester of 2018/2019 and 2019/2020 and laboratory IVB in the second semester of 2016/2017).

The aim of the present paper is to present how the SparkPlus tool for self and peer assessment of students of laboratory curricular unit was employed to examine the evolution of student's assessment skills over 3 years implementation, and also to identify the skills students need to develop further.

\section{METHODOLOGY}

\subsection{Study sample}

Students of Biotechnology Bachelor course attending laboratory classes in their second year sampled for three years 2016/2017, 2018/2019 and 2019/2020. The student under study are characterized according to gender, age, and working or not status, as shown in Table 1 . Every year students were distributed for three classes in the laboratory. In 2016/2017, there were a total of 52 students, in 2018/2019, a total of 45 students, and finally in 2019/2020, there were a total of 42 students. Moreover, the number of students per group was similar throughout the three years, mostly 3 to 5 students per group. 
Table 1. Characterization of the student sample throughout the academic years.

\begin{tabular}{l|c|c|c|c|c|c}
\hline \hline Academic year & \multicolumn{2}{|c|}{$2016 / 2017$} & \multicolumn{2}{c|}{$2018 / 2019$} & \multicolumn{2}{c}{$2019 / 2020$} \\
\hline Parameters & $\mathrm{Nr}$. & $\%$ & $\mathrm{Nr}$. & $\%$ & $\mathrm{Nr}$. & $\%$ \\
\hline Males & 14 & 26.9 & 17 & 37.8 & 17 & 40.5 \\
\hline Females & 38 & 73.1 & 28 & 62.2 & 25 & 59.5 \\
\hline Average age (years) & 22.3 & & 21.1 & & 22.5 & \\
\hline 20 -23 years old & 37 & 71 & 42 & 93 & 36 & 86 \\
\hline $\mathbf{2} 24$ years old & 15 & 29 & 3 & 7 & 6 & 14 \\
\hline Working Student & 6 & 11.5 & 6 & 13.3 & 4 & 9.5 \\
\hline \hline
\end{tabular}

\subsection{Self and peer assessment tool}

All students were required to complete an online survey using the SparkPlus tool [2] in the last week of class, regarding the reports and the laboratory work they had performed during the semester. They were asked to rate their own and their peer's performance within the same group, according to four criteria categories stated in table 2. Students rated all these criteria using a slider scale from Well Below Average (WB) to Well Above Average (WA). The scale corresponded to NC $0-4 \%$, WB $4-$ $28 \%$, BA $28-52 \%$, AV $52-76 \%$, AA $76-100 \%$.

Table 2. Category criteria.

\begin{tabular}{l|l}
\hline \hline 1. Efficient functioning of group: \\
\hline 1. a) & Helping the group to function as a team \\
\hline 1. b) & Maintain the level of enthusiasm and participation \\
\hline 1. c) & Organizing the team and ensuring that tasks were performed \\
\hline 1. d) & Performing tasks efficiently, suggesting ideas \\
\hline 1. e) & Understanding what is required for a given task \\
\hline 2. Leadership: \\
\hline 2. a) & Chasing and coordinating \\
\hline 2. b) & assignment of tasks to each member and decide deadline dates to gather information \\
\hline 2. c) & Integrating the developed work to answer a given problem or to write a report \\
\hline 3. Number crunching: \\
\hline 3. a) & Analysis and cross checking \\
\hline 3. b) & Data and formula entry, and formatting \\
\hline 3. c) & Finding out how to solve a given problem \\
\hline 3. d) & Getting new data \\
\hline 4. Writing the report: \\
\hline 4. a) & editing format, style, grammar, spelling \\
\hline 4. b) & getting extra references and appraising their usefulness \\
\hline 4. c) & producing diagrams, figures, tables \\
\hline 4. d) & Typing \\
\hline \hline
\end{tabular}

\subsection{Quantification of each student contribution}

SparkPlus calculates the Relative Performance Factor (RPF) (see Introduction) and the SelfAssessment to Peer-Assessment factor (SA/PA) which accounts for self-rating in each group, as an overall factor or partial factor for each criterion category.

The Relative performance factor was then used to obtain the individual classification of each student according to calculation: 
Individual classification = Team classification* Individual's RPF

At the completion of the semester, the teacher provided students with their RPF and SA/PA results to help students reflect on their performance both within the group and for individual criteria used in the assessment.

\section{RESULTS}

\subsection{Students self and peer assessment}

The results obtained in the present study represent the large majority of students enrolled in laboratory classes of the second year of Biotechnology Bachelor course from the academic year of 2016/2017, 2018/2019 and 2019/2020.

In Table 3, it is shown that throughout the three academic years, there is a similar but not significant number of students that overrated their contribution to assignments, compared with the opinion of their group members (SA/PA >1.1).

Table 3. Study sample and Over- and Under-rated Students.

\begin{tabular}{c|c|c|c|c}
\hline \hline Year & $\begin{array}{c}\text { Total } \\
\text { students }\end{array}$ & $\begin{array}{c}\text { Total } \\
\text { answers }\end{array}$ & $\begin{array}{c}\text { Underrated Students } \\
\text { SA/PA<0.9 }\end{array}$ & $\begin{array}{c}\text { Overrated Students } \\
\text { SA/PA>1.1 }\end{array}$ \\
\hline $2016 / 2017$ & 51 & $86 \%$ & 0 & $9(7 \mathrm{~F}+2 \mathrm{M})$ \\
\hline $2018 / 2019$ & 45 & $87 \%$ & $9(5 \mathrm{~F}+4 \mathrm{M})$ & $7(6 \mathrm{~F}+1 \mathrm{M})$ \\
\hline $2019 / 2020$ & 42 & $90 \%$ & $2(2 \mathrm{M})$ & $9(4 \mathrm{~F}+5 \mathrm{M})$ \\
\hline \hline
\end{tabular}

Over confidence can promote such results. On the other hand, underrated students $(\mathrm{SA} / \mathrm{PA}<0,9)$ were seen only in the last 2 academic years and the number is much lower than the opposite situation (vide Table 3). These results didn't correlate with final grades, neither age nor gender, as the majority of students were female, they tend to be the majority to overrate or underrate.

In 2019/2020, the majority of students present a self-rating (SA/PA) between 0.94 and 1.04 (Fig. 1), which means student's self-assessment is within approximately $10 \%$ of their peers' assessment of $\mathrm{him} / \mathrm{herself}$, reflecting that self-assessment of the student's own contribution is roughly in agreement with the average assessment of his contribution by the team [5].

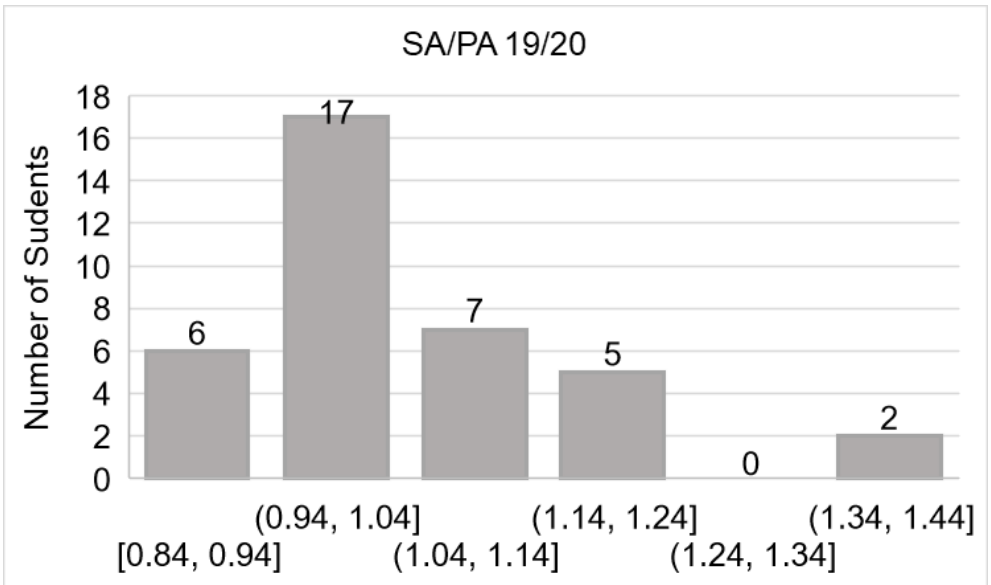

Figure 1. Histogram of Self-Assessment to Peer-Assessment factor (SA/PA) for year 2019/2020.

On the contrary in the two previous years, self-assessment of the majority of students fell into lower ranges of values (Fig. 2 and Fig. 3, higher column in each histogram) meaning they were underestimating their own contribution. For this fact, one can say that there was a positive evolution on the self-awareness about the students' own contribution over the years. 


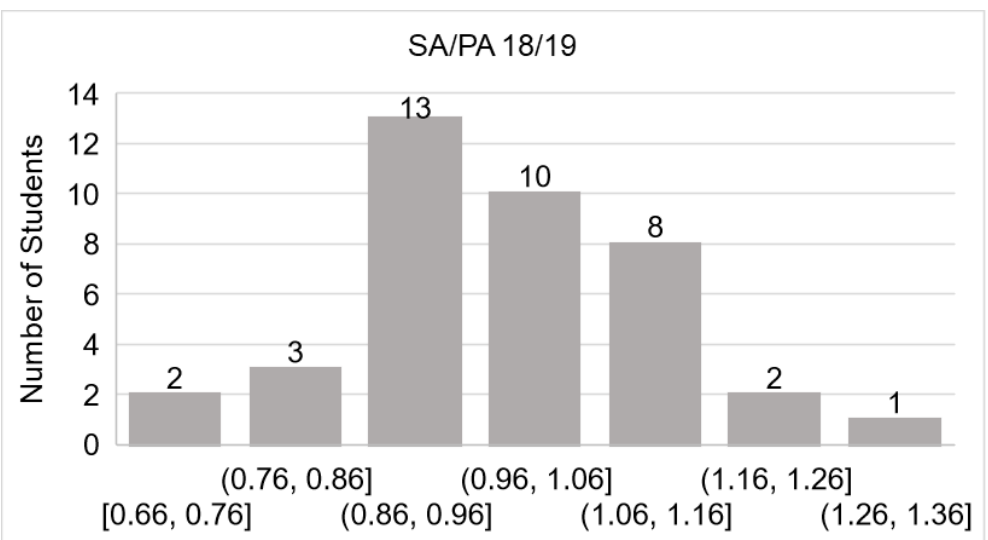

Figure 2. Histogram of Self-Assessment to Peer-Assessment factor (SA/PA) for year 2018/2019.

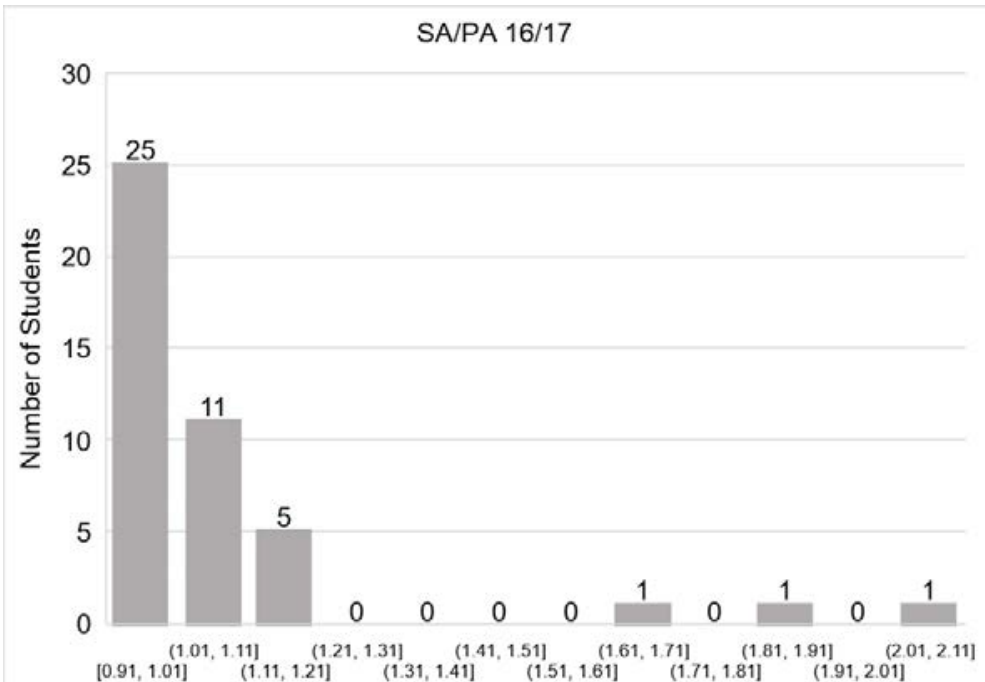

Figure 3. Histogram of Self-Assessment to Peer-Assessment factor (SA/PA) for year 2016/2017.

Peer-rating (RPF) showed that the majority of students fall between 0.94 and 1.04 over the 3-years implementation of self and peer assessment, which means an average contribution to the team work. Moreover, the majority RPF's values moved from a lower value (0.91) to higher value (1.04) throughout the 3 academic years (Fig. 6, Fig. 5 and Fig. 4). These findings indicate that the majority of students were self-aware and recognised each member's contribution to the team work inside their group. Only a small number of cases were identified by SparkPlus as needing to improve these skills. In 2019 /2020: there was only one case of a student low contribution to their team work which can be shown by a relative performance factor lower than 0.9 , there were none in 2018/2019, and 4 students (cases) in 2016/2017.

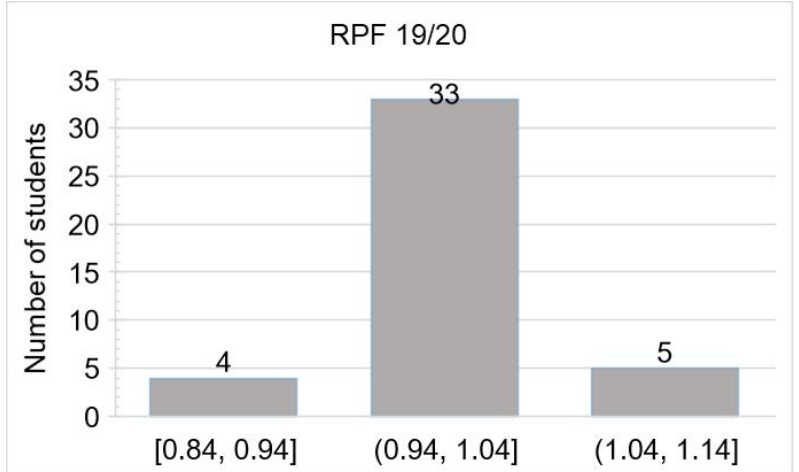

Figure 4. Histogram of Self-Assessment to Peer-Assessment factor (SA/PA) for year 2016/2017. 


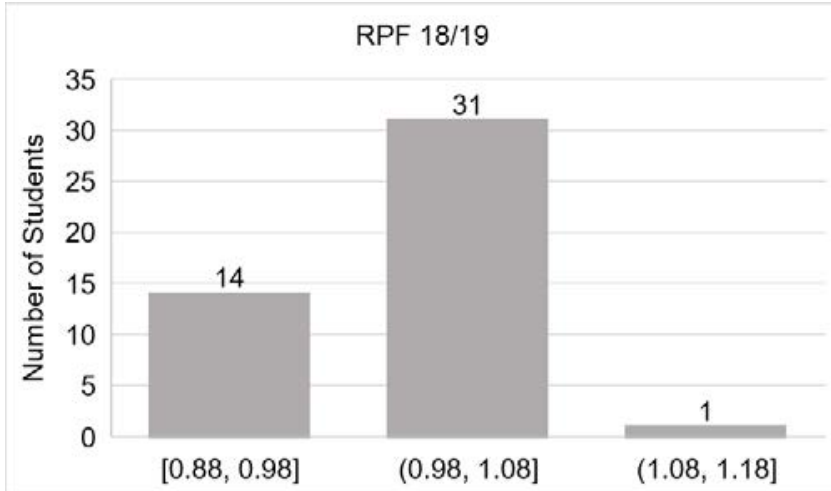

Figure 5. Histogram of Relative Performance factor (RPF) for year 2018/2019.

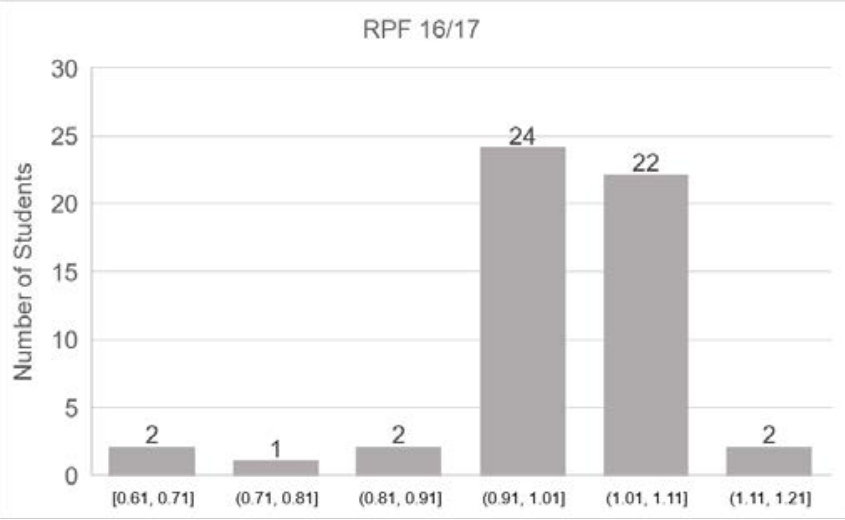

Figure 6. Histogram of Relative Performance factor (RPF) for year 2016/2017.

The individual RPF was applied in the final evaluation of the laboratory's curricular unit, in the written reports submitted by the group, which allowed instructors to differentiate the student's classification according to his or her contribution to the team work. Only one student said that assessment from their peers was subjective and for this reason it wasn't valid to lower his classification.

Looking into detail on 2019/2020 year, students performed in team work in a balanced way as can be shown in Fig. 7, meaning that this particular group obtained RPF in the $10 \%$ around the average, although the SA/PA was not equal balanced.

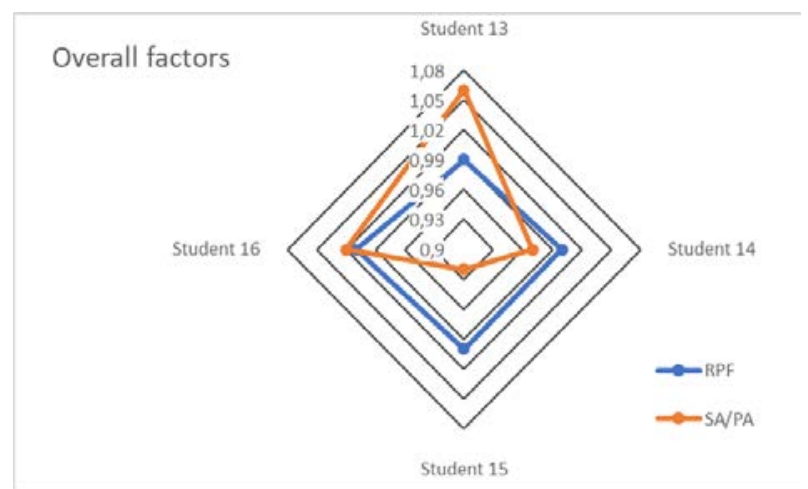

Figure 7. Relative Performance Factor (RPF) and Self-Assessment to Peer Assessment factor (SA/PA) of a group of 4 participants from 19/20.

In the same year, dysfunctional groups were identified and can be observed in Fig. 8 and Fig. 9, meaning that some members of these groups have an RPF outside the $10 \%$ around the average. These results seem to be independent of the number of participants per group, but each group has one worker student that are also older than the average. 
Moreover, instructors need to know which skills students are lacking regarding team work, as these are the key to accomplish the laboratory classes of Biotechnology Bachelor course with success, as explained in the previous case study [8].

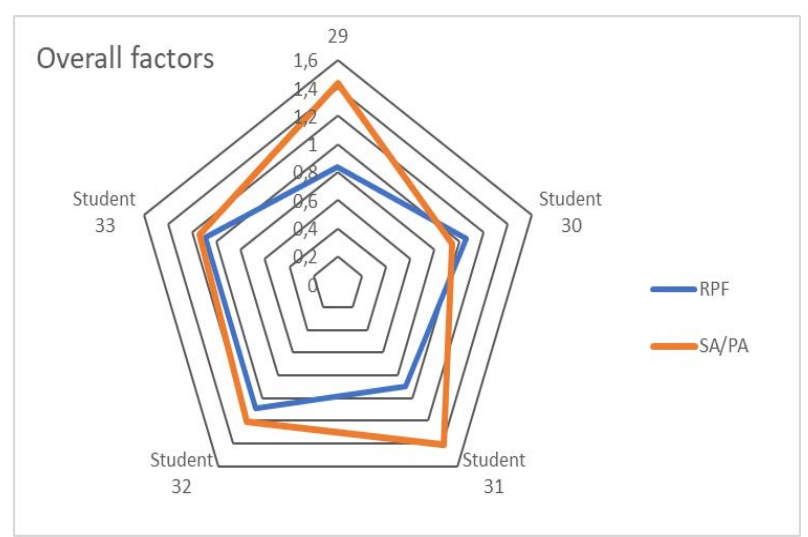

Figure 8. Relative Performance Factor (RPF) and Self-Assessment to Peer Assessment factor (SA/PA) of a group of 5 participants from 19/20.

In order to find that, it is presented in Table 4, the overall factors by each criterion for the dysfunctional group in Fig. 8. The radar graph presented for student 29 (Fig. 10) from the same group shows all criteria had a low RPF value below 0.95 , particularly the writing report criterion had the lowest value. This student is a case of low contribution to group work although he rates himself very highly.

Table 4. Students' RPF and SA/PA of a group of 5 participants from 19/20, same as in Fig. 8.

\begin{tabular}{c|c|c|c|c|c|c|c|c}
\hline \multirow{2}{*}{$\begin{array}{c}\text { Student } \\
\text { Nr. }\end{array}$} & $\begin{array}{c}\text { Leadership } \\
25 \%\end{array}$ & \multicolumn{2}{|c|}{$\begin{array}{c}\text { Efficient functioning of } \\
\text { group } 25 \%\end{array}$} & $\begin{array}{c}\text { Number crunching } \\
25 \%\end{array}$ & \multicolumn{2}{|c}{$\begin{array}{c}\text { Writing report } \\
25 \%\end{array}$} \\
\cline { 2 - 9 } & RPF & SA/PA & RPF & SA/PA & RPF & SA/PA & RPF & SA/PA \\
\hline 29 & 0.82 & 1.64 & 0.9 & 1.13 & 0.82 & 1.56 & 0.76 & 1.86 \\
\hline 30 & 1.05 & 0.9 & 1.04 & 0.91 & 1.11 & 1.01 & 1.06 & 0.95 \\
\hline 31 & 0.94 & 1.43 & 0.94 & 1.23 & 0.86 & 1.36 & 0.81 & 1.85 \\
\hline 32 & 1.08 & 1.32 & 1.06 & 1.25 & 1.11 & 1.1 & 1.12 & 1.19 \\
\hline 33 & 1.08 & 1.2 & 1.05 & 1.2 & 1.05 & 1.1 & 1.17 & 1.07 \\
\hline \hline
\end{tabular}

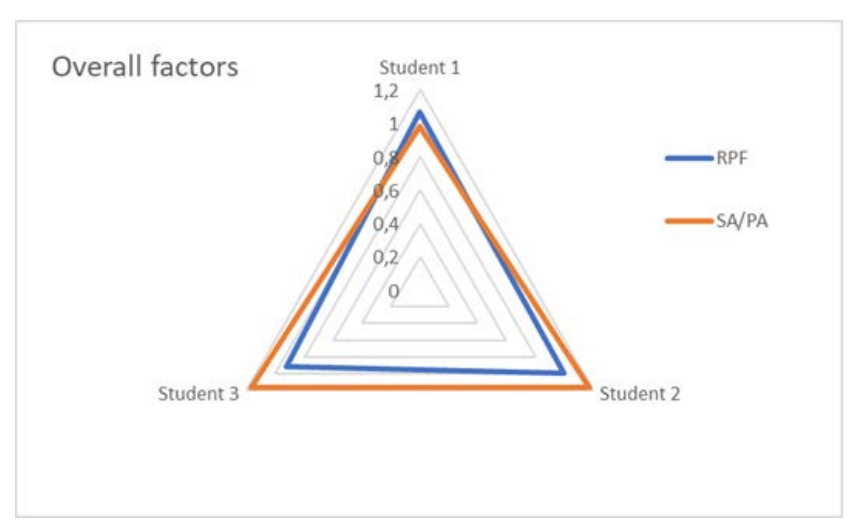

Figure 9. Relative Performance Factor (RPF) and Self-Assessment to Peer Assessment factor (SA/PA) of a group of 3 participants from 19/20. 


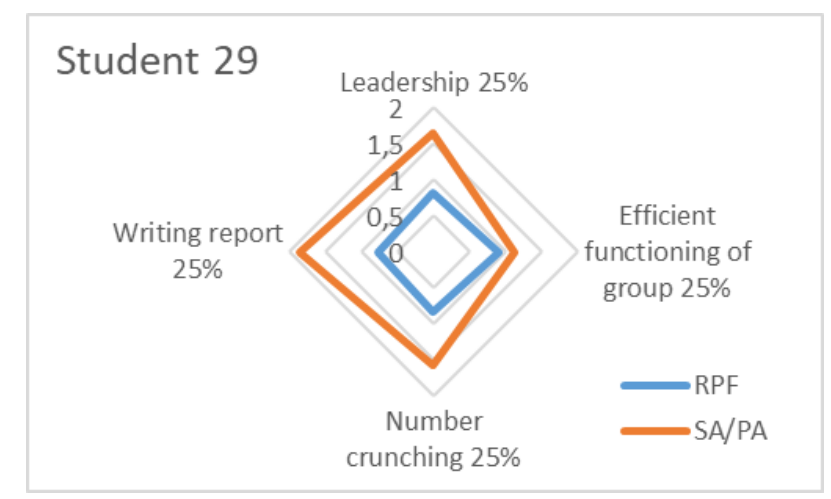

Figure 10. Relative Performance Factor (RPF) and Self-Assessment to Peer Assessment factor (SA/PA) for student 29 from 19/20.

When looking into criteria category ratings (Table 5) the highest variations (difference between the maximum and the minimum values) are registered first of all at the writing report, secondly the leadership, and thirdly the number crunching. These criteria categories showed more difficulties among the students meaning that there is a need to develop and practice them during the course. On the other hand, the smallest amplitude was registered for the efficient functioning of group, meaning that this skill was acquired by students.

Table 5. Students' RPF from 2019/2020.

\begin{tabular}{c|c|c|c|c}
\hline \hline \multicolumn{1}{c|}{$R P F$} & Leadership & $\begin{array}{c}\text { Efficient functioning } \\
\text { of group }\end{array}$ & $\begin{array}{c}\text { Number } \\
\text { crunching }\end{array}$ & Writing report \\
\hline Maximum & 1.13 & 1.08 & 1.11 & 1.17 \\
\hline Minimum & 0.82 & 0.89 & 0.82 & 0.76 \\
\hline Variation & 0.31 & 0.19 & 0.29 & 0.41 \\
\hline \hline
\end{tabular}

From the teacher's point of view, the results offered a validation of the teamwork perception obtained from observations during classes. Moreover, the results added new information about the skills students lacked at that stage of course. This new information can be used to restructure future classes in order to practice these skills.

\section{CONCLUSIONS}

The present work was performed over 3 academic years, in which the majority of students showed evidence of good teamwork skills. The process as implemented allowed the instructor to identify poorly functioning groups and analyse the underlying causes for these results and be aware for future years. Nevertheless, in order to really make a change and empower students with the required skills to function in teams, one has to study a given student sample for a broader period of time and set goals. Therefore, the present work aims to lay the foundations to a more systematic approach, in which the authors analyse SparkPlus data from students of the bachelor course in Biotechnology from the first year. This approach will allow us to assess the evolution of the students' team work skills from the beginning of their course until their graduation and to develop them in a consistent way. At the end of each semester, the results of underperforming groups are going to be identified and the reasons for the results obtained will be investigated. These observations will allow us to set new tasks in order to overcome the encountered problems and improve how students work as a team.

Regarding the results obtained, the writing of the laboratory reports gathered the lowest RPF values, which is consistent with the main observed difficulties of the students. In order to improve the writing skills, the laboratory teacher should encourage the writing of topics in the laboratory notebook, to better structure the final text and provide feedback. To improve the "Data crunching" category, the teacher should also discuss the laboratory results in class and introduce some software tools, in order to students gain more confidence in treating the obtained results. Concerning the "Leadership" skill, the creation of the leader figure in each laboratory group which is alternating between all group 
members will be proposed. The best leader will be the one with the best results (RPF and SA/PA around 0.95 and 1.05 , respectively).

From the student's point of view the effect of the RPF in the evaluation was rewarding and fairer, as students said to teacher during classes.

The process allowed the instructor to identify poorly functioning groups and be aware of possible issues for future years.

\section{ACKNOWLEDGEMENTS}

The authors would like to acknowledge Professor Pedro Neto and Professor Bill Williams for introducing and supporting the Sparkplus online tool at our school.

\section{REFERENCES}

[1] K. Willey and A. Gardner, "Investigating the capacity of self and peer assessment activities to engage students and promote learning", European Journal of Engineering Education, vol. 35, no. 4, pp. 429-443, 2010.

[2] P. Neto, B. Williams, and I. Carvalho, "Encouraging and monitoring student engagement during interdependent and intradependent team-work", Proc. of the SEFI Annual Conference 2011, Lisbon, Portugal. vol. 2, pp. 120-128, 2011.

[3] P. Neto and B Williams, "More activity, less lectures: A technology stewardship approach applied to undergraduate engineering learning", 1st International Conference of the Portuguese Society for Engineering Education (CISPEE), pp. 1-5, Porto, Portugal, IEEE, 2013.

[4] K. Willey and M. Howard, "SPARKplus Power to learn User Guide", University of Sydney, 2018. Retrieved from https://help.online.uts.edu.au/wp

[5] K. Willey, "SparkPlus Supporting Resources Version 3.1", University of Sydney, pp. 10. 2018. Retrieved from http://sparkplus.com.au/fac

[6] E.F. Gehringer, "Self-Assessment to Improve Learning and Evaluation", American Society for Engineering Education (ASEE), Adelaide, Australia, pp. 1-9, 2017.

[7] B. Beamish, M. Kizil, K. Willey, and A. Gardner, "Monitoring mining engineering undergraduate perceptions of contribution to group project work", 20th Australasian Association for Engineering Education Conference (AAEE), pp. 318-325, 2009.

[8] C.A. Santos, and A.G. Gomes, "Evaluation of group work in the Chemistry and Biotechnology laboratory", Book of abstracts of the 3rd International Conference of the Portuguese Society for Engineering Education (CISPEE), Aveiro, Portugal, 2018. 